\title{
New Evidence On Hedge Fund Performance Measures
}

\author{
Komlan Sedzro, University of Quebec in Montreal, Canada
}

\begin{abstract}
Hedge funds are still relatively unfamiliar to most investors despite the intense popularity they have enjoyed in recent years. Measuring the performance of these financial instruments using traditional methods is, however, problematic, since their returns do not follow a normal distribution. In this study, we consider rankings obtained with the Stochastic Dominance (SD) method and compare them with ranks produced using Sharpe Ratios, Modified Sharpe Ratios, and Data Envelopment Analysis. We also explore the advantages highlighted by the literature of the Data Envelopment Analysis (DEA) method in relation to traditional measures like Sharpe ratio and Modified Sharpe ratio. Our results show that classic performance measures are better correlated with $S D$ than DEA results.
\end{abstract}

Keywords: Data Envelopment Analysis, Performance Evaluation, Stochastic Dominance, Hedge Funds.

\section{INTRODUCTION}

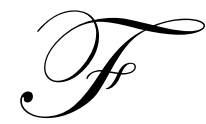

ollowing the stock market turbulence of the recent years, alternative investments have become the latest trend among traders. The number of hedge funds (HF) and the value of assets under HF management rose from 600 funds managing $\$ 38$ billion in 1990 to more than 10,000 funds valuing more than $\$ 1,500$ billion in 2006 (Crockett, 2007), representing growth of over 1000\% in 16 years.

The size of the HF industry justifies this study, as well as the differences in the results obtained using traditional measures to evaluate the performance of this asset class. Indeed, many studies have shown that HFs outperform both mutual funds and traditional investments, based on returns or risk-adjusted returns (Cottier 2000; Liang 1999; Caglayan and Edwards 2001; and Agarwal and Naik 2000a). However, some authors (Ackermann, McEnally, and Ravenscraft, 1999, Brown, Goetzmann, and Ibbotson 1999) report a less conclusive performance for hedge funds. These diverging observations could be because the results are based on different performance measures.

Indeed, financial literature proposes several tools to measure the performance of mutual or hedge funds. To start with, there are the traditional measures, like the Sharpe, Jensen or Treynor ratios (Elton and Gruber, 1995; Sharpe, 1966). Measures like the Modified Sharpe ratio suggested by Favre and Galeano (2002) that take into account skewness in return distributions also exist but are more complex. Moreover, Gregoriou, Sedzro, and Zhu (2005) have recently proposed Data Envelopment Analysis (DEA), a non-parametric method often used to assess the efficiency of public sector decision-making units, as a useful measure for evaluating hedge fund performance. Another more general measure is the stochastic dominance (SD) used by Wong, Phoon, and Lean (2008) to compare the performance of Asian hedge funds. Although involving time consuming pairwise comparison between any pair of hedge funds, SD is a more powerful performance measure because it incorporates information on the entire return distribution (Post, 2003; Davidson and Duclos, 2000).

Therefore, the objective of this study is to test the effectiveness of traditional measures and the DEA scores to assess hedge fund performance using stochastic dominance as benchmark. More specifically, we will compare hedge fund performance using the Sharpe ratio, Modified Sharpe and DEA, with the rankings obtained using stochastic dominance. To our knowledge, this question has not been raised in previous studies. 
The remainder of this paper is organized as follow: Section 2 provides a general overview of hedge funds. Section 3 presents the data and methodology used to measure HF performance. Section 4 presents our findings, followed in section 5 by a brief conclusion.

\section{BACKGROUND}

HF performance has been the subject of scrutiny in the literature, with most authors demonstrating that their risk-adjusted returns are better than most of the stock market indices. For example, Table 1 compares the performance of a hedge fund (Marhedge index Fund of Funds) with the S\&P 500 index.

Table 1: S\&P 500 vs. Marhedge index of Fund of Funds (1990-2001)

\begin{tabular}{lcc}
\hline Measures & S\&P 500 & Marhedge index of Fund of Funds \\
\hline Total return & $246.50 \%$ & $221.80 \%$ \\
Annual compounded return & $11.41 \%$ & $10.70 \%$ \\
Annual Standard deviation & $14.27 \%$ & $4.61 \%$ \\
Sharpe ratio & 0.45 & 1.24 \\
Monthly average return & $0.99 \%$ & $0.86 \%$ \\
Return (Best month) & $11.16 \%$ & $4.50 \%$ \\
\% month with positive returns & $64.59 \%$ & $81.88 \%$ \\
Average return (month with positive returns) & $3.38 \%$ & $1.28 \%$ \\
Average return (month with negative returns) & $-3.36 \%$ & $-1.03 \%$ \\
\hline
\end{tabular}

Cottier (2000) observes that with an annualized return of $17.86 \%$ with $9.81 \%$ volatility, HFs are better than both mutual funds and traditional investments, based on returns or risk-adjusted performance. He argues that HF overachievement could be explained by the prohibitive fees charged by fund managers and the difficulty of withdrawing money from the funds. In the same vein, Liang (1999) observes that out of 16 HF strategies analyzed, seven exhibited non-normal returns, varying between $7.68 \%$ and $15.12 \%$ per year. Liang (1999) also notes that the high incentive fee structure of HF managers generates superior returns compared to funds that do not offer such generous incentives.

Agarwal and Naik (2000a) also show that 10 out of $10 \mathrm{HF}$ strategies generate significant positive excess return above risk free rate, varying between $6.36 \%$ and $15 \%$ per year. However, by examining more thoroughly the HF performances, Agarwal and Naik (2000b) concluded that the persistence in the outperformance was more evident in the short term and tended to diminish in the long term. They also found that this persistence did not seem to be linked to HF strategies and was even less evident in a multi-period framework.

Furthermore, Ackermann, McEnally, and Ravenscraft (1999) find that HF performance surpasses that of mutual funds, but not that of a market benchmark. Brown, Goetzmann, and Ibbotson (1999) also report an underperformance of offshore hedge funds between 1989 and 1995 compare to the S\&P 500 index. These contradictory findings could be explained, at least partially, by the different performance measures used in these studies.

\section{DATA AND METHODS}

\subsection{Data}

The data, from Hedge Fund Research (HFR) database, covers a 36-month period (August 2000 to July 2003) and a 60-month period (August 1998 to July 2003) and includes 615 hedge funds in nine categories. 21 in Convertible Arbitrage; 26 in Distressed Securities; 195 in Equity Hedge; 48 in Event-driven; 50 in Fixed Income Arbitrage; 182 in Funds of funds; 35 in Global Macro; 46 in Market Neutral; and 12 in Short-Selling. We conducted tests in the different categories to identify similarities and divergences. The database contains monthly returns, the asset under management, and the category of each hedge fund. 
We used the 1-Month Certificate of Deposit (Secondary Market rates posted on the website of the Federal Reserve Bank of St. Louis) as risk-free monthly rates to calculate the Sharpe and Modified Sharpe ratios.

\subsection{Methods}

We examined rankings obtained from three performance measures: the Sharpe ratio, the Modified Sharpe ratio, and the efficiency score obtained using the DEA method. The three sets of ranks were compared with the ranking obtained using stochastic dominance methodology.

\subsubsection{The Sharpe ratio}

The Sharpe ratio $\left(S_{P}\right)$ is calculated as follows:

$$
S_{P}=\frac{R_{p}-R_{f}}{\sigma_{R p}}
$$

Where:

$$
\begin{array}{lll}
R_{P}= & \text { Return of the portfolio } \\
R_{f}= & \text { Risk-free rate } \\
\sigma_{R p}= & \text { Standard deviation of portfolio return }
\end{array}
$$

It is important to note here that the Sharpe ratio is based on the assumption that the distribution of return is normal. Standard deviation is therefore a representative measure of risk. However, HF managers often employ various strategies that can alter the distribution of return (for example, the purchase, or sale of derivative products). It would therefore appear that this ratio might not be a "good" performance indicator for HF.

To mitigate the problem of deviation from normality, Favre and Galeano (2002) propose the Modified Sharpe ratio that, as a measure of risk, takes into account the standard deviation, the skewness, and the kurtosis of the distribution of returns.

\subsubsection{The Modified Sharpe ratio}

The Modified Sharpe ratio is calculated as follows:

$$
\text { Modified Sharpe ratio }=\frac{R_{p}-R_{f}}{R_{p}+\left(\sigma_{R p} \times M V a R\right)}
$$

Where

$$
\begin{array}{ll}
\text { MVaR= } & z_{c}+\frac{1}{6}\left(z_{c}^{2}-1\right) S+\frac{1}{24}\left(z_{c}^{3}-3 z_{c}\right) K-\frac{1}{36}\left(2 z_{c}^{3}-\right. \\
\text { MVaR } & =\text { Modified Value-at-Risk. } \\
Z_{c} & =\text { Standard normal score for a confidence level of }(1-\alpha) . \\
\mathrm{S} & =\text { Skewness of the distribution of portfolio's return. } \\
\mathrm{K} & =\text { Excess kurtosis of the distribution of portfolio's return. } \\
\sigma_{\mathrm{Rp}} & =\text { Standard deviation of portfolio's return. } \\
\mathrm{R}_{\mathrm{p}} & =\text { Return of the portfolio. }
\end{array}
$$


The Modified Sharpe ratio is expected to address the issue of non-normality of returns of hedge funds through the MVaR variable. The MVaR is similar to the classic Value-at-Risk (VaR), but is supposed to give better results in cases of assets with extreme negative returns. Note that VaR represents the maximum potential loss of an investment over a particular time horizon, and a given confidence level.

\subsubsection{The Data Envelopment Analysis}

Charnes, Cooper, and Rhodes (1978) have developed this method to evaluate the relative efficiency of nonprofit and public sector management units using similar inputs to produce a range of outputs. Since then, it was applied in different sectors: hospitals (Banker, Conrad, and Strauss, 1988), food services (Banker, Kaufman, and Morey 1986), education (Bessent and Bessent 1980), banking (Sherman and Gold 1985), etc.

The DEA method could be very useful in evaluating investment funds (Murthi, Choi, and Desai, 1997). In our case, we will use this method to identify the best performing hedge funds and rank them. However, before proceeding any further, we must explain the DEA technique in more detail because it is relatively unknown in the financial literature.

The DEA technique is a nonparametric method for estimating frontiers that can be useful to measure the performance of entities using several inputs and generating multiple outputs. More specifically, the DEA method can be summarized as follows: a group of companies or entities (often referred to as Decision-Making Units or DMUs) is observed and their relevant inputs and outputs are identified. Using linear programming, the position of each unit is established in relation to the optimal DMU that is a fictitiously created ideal unit producing a given quantity of outputs using a minimum amount of inputs. A dual approach involves finding the unit that, with a given amount of inputs, produces the maximum output.

Charnes, Cooper, and Seiford (1995) noted that this method focuses more on individual observations than on the average of a given population. It produces a single aggregate measure for each decision-making unit and considers, without the constraints of the size or the scale, the features of multiple inputs and multiple outputs of production activities.

The algebraic formulation of this method is as follows:

$\min \theta_{o}$

Subject to

$\sum_{j=1}^{n} \lambda_{j} X_{i j} \leq \theta_{o} X_{i o} \quad \mathrm{i}=1,2 \ldots \mathrm{m}$;

$\sum_{j=1}^{n} \lambda_{j} Y_{r j} \geq Y_{r o} \quad \mathrm{r}=1,2 \ldots \mathrm{s}$

$\sum_{j=1}^{n} \lambda_{j}=1$

$\lambda_{j} \geq 0 \quad \mathrm{j}=1,2 \ldots \mathrm{n} ;$

Where

$\mathrm{o}=\quad$ the index of the HF under analysis

$\mathrm{s}=\quad$ number of outputs produced by HFs;

$\mathrm{m}=\quad$ number of inputs used by HFs;

$y_{\mathrm{rj}}=\quad$ the amount of $\mathrm{r}^{\text {th }}$ output obtained by the $\mathrm{j}^{\text {th }}$ hedge fund;

$\mathrm{x}_{\mathrm{ij}}=$ the amount of $\mathrm{i}^{\text {th }}$ input used by the $\mathrm{j}^{\text {th }}$ hedge fund;

$\lambda_{j}$ is a weighting allotted to $j^{\text {th }}$ hedge fund which helps to determine the fictitiously created ideal HF with efficiency of 1 . 
No DMU efficiency score may exceed one when the computed weights are applied. The efficiency score therefore makes the performance of each DMU appear as strong as possible. DMUs lying on the frontier have an efficiency score of one and inefficient units have a score of less than one. Results produced using the DEA technique, therefore, are easy to interpret because they are always between zero and one.

The DEA method gives the same score of one, however, to all DMUs lying on the efficiency frontier. For example, in a sample of 200 decision-making units, it is very likely that we will find 15 DMUs with a score of one, which makes it difficult to rank the best hedge funds. To correct this, in our study we use the "super-efficiency" DEA model introduced by Anderson and Petersen (1993). This calculation is identical to the standard DEA score for inefficient units, but it differs to that of efficient DMUs. The super-efficiency DEA generates a ratio higher than one for efficient units, providing us with a complete classification.

We individually analyzed 615 hedge funds, enabling us to obtain the efficiency level for each of them within their respective categories. Following Gregoriou et al. (2005) we employed as inputs: Average, standard deviation (semi-variance) and skewness (semi-skewness) of monthly returns below the monthly risk-free rates. For outputs, we also employed the average, standard deviation and skewness, but for returns above the risk-free rates.

\subsubsection{Stochastic dominance}

The fourth method we have considered in this study is stochastic dominance (Davidson and Duclos, 2000; Wong et al., 2008). It is a nonparametric approach and do not requires any explicit specification of a utility function or probability distribution functional form. According to Taylor and Yoder (1999), SD is a theoretically unimpeachable general model of portfolio choice that maximizes expected utility. Similarly, Meyer et al. (2005) state that "SD is theoretically superior to mean variance analysis because it considers the entire return distribution and is based on minimally restrictive assumptions regarding investor motives".

However, SD is little used in practice, probably because it can quickly become cumbersome to manage when the sample size increase. Indeed, it requires a binary comparison of the entire return distribution of each hedge fund relative to the others. This is done using first, second or third order stochastic dominance. With first order, the goal is to identify the best possible return regardless of risk. With second order, the aim is to find the best return/risk combination. Third order stochastic dominance is based on the premise that risk aversion diminishes in proportion to the investor's wealth.

\subsubsection{Comparison methods}

We selected three hedge fund performance measures for our comparative analysis. Namely, the Sharpe ratio, the Modified Sharpe ratio, and the DEA efficiency score. We began with a numerical ranking of each hedge fund based on the evaluation arising from each performance measure. We then made a comparative analysis by calculating the correlation coefficient.

The Spearman Rank Correlation among these rankings was calculated as follows:

$$
\rho_{x y}=\frac{\operatorname{Cov}(X, Y)}{\sigma_{X} \sigma_{y}}
$$

Where:

$-1 \leq \rho_{X Y} \leq 1$

$\mathrm{X}$ and $\mathrm{Y}=$ the numerical rankings of hedge funds according to a particular performance measure.

$\operatorname{Cov}(X, Y)=\frac{1}{n} \sum_{i=1}^{n}\left(X_{i}-\mu_{x}\right)\left(Y_{i}-\mu_{Y}\right)$ 


\section{$4 \quad$ RESULTS}

\subsection{Sample of performance measures and ranks}

Tables 2 and 3 present the measures and the ranks of 46 hedge funds in a Market Neutral category over three and five-year periods, respectively. To save space, other categories results are available from the author. The findings in bold face represent the five most efficient HFs according to each measure. We observed that for the 3year period, the ranking of the five best HFs was the same, whether we employed the Sharpe ratio or the Modified Sharpe ratio. However, ranking these funds using the DEA score produces different results. These observations apply also to the 5-year period with only a few exceptions.

Table 2: Market Neutral performance (3 years)

\begin{tabular}{|c|c|c|c|c|c|c|c|}
\hline Funds & Sharpe ratio & $\begin{array}{l}\text { Modified } \\
\text { Sharpe }\end{array}$ & DEA ratio & $\begin{array}{c}\text { Super-DEA } \\
\text { ratio }\end{array}$ & $\begin{array}{c}\text { Sharpe } \\
\text { Ranking }\end{array}$ & $\begin{array}{c}\text { Modified } \\
\text { Sharpe Ranking }\end{array}$ & $\begin{array}{c}\text { Super-DEA } \\
\text { Ranking }\end{array}$ \\
\hline 144001 & 0.06 & 0.02 & 0.40 & 0.40 & 26 & 26 & 18 \\
\hline 144201 & 0.08 & 0.03 & 0.47 & 0.47 & 22 & 25 & 9 \\
\hline 146701 & 0.37 & 0.13 & 0.54 & 0.54 & 6 & 7 & 5 \\
\hline 146901 & 0.19 & 0.08 & 0.31 & 0.31 & 13 & 12 & 25 \\
\hline 166301 & -0.04 & -0.01 & 0.39 & 0.39 & 34 & 35 & 22 \\
\hline 169101 & 0.13 & 0.07 & 0.19 & 0.19 & 15 & 14 & 41 \\
\hline 189501 & 0.14 & 0.07 & 0.47 & 0.47 & 14 & 15 & 10 \\
\hline 20201 & 0.72 & 0.20 & 1.00 & 1.24 & 1 & 1 & 3 \\
\hline 204001 & 0.13 & 0.07 & 0.19 & 0.19 & 16 & 13 & 43 \\
\hline 219401 & 0.07 & 0.04 & 0.19 & 0.19 & 25 & 22 & 42 \\
\hline 25901 & -0.08 & -0.06 & 0.21 & 0.21 & 39 & 40 & 39 \\
\hline 26001 & -0.30 & -0.15 & 0.41 & 0.41 & 45 & 45 & 16 \\
\hline 271201 & -0.15 & -0.07 & 0.26 & 0.26 & 43 & 41 & 31 \\
\hline 274901 & 0.09 & 0.04 & 0.30 & 0.30 & 20 & 20 & 26 \\
\hline 300101 & -0.06 & -0.03 & 0.25 & 0.25 & 38 & 38 & 35 \\
\hline 334101 & 0.06 & 0.02 & 0.48 & 0.48 & 27 & 27 & 8 \\
\hline 346501 & -0.06 & -0.02 & 0.39 & 0.39 & 37 & 36 & 21 \\
\hline 350801 & -0.06 & -0.03 & 0.23 & 0.23 & 36 & 37 & 37 \\
\hline 370601 & -0.02 & -0.01 & 0.40 & 0.40 & 32 & 32 & 17 \\
\hline 382001 & -0.15 & -0.13 & 0.10 & 0.10 & 42 & 44 & 46 \\
\hline 382101 & 0.39 & 0.15 & 0.42 & 0.42 & 5 & 5 & 15 \\
\hline 382401 & 0.19 & 0.07 & 0.51 & 0.51 & 12 & 16 & 7 \\
\hline 390201 & 0.32 & 0.10 & 0.46 & 0.46 & 8 & 11 & 13 \\
\hline 398501 & 0.02 & 0.01 & 0.28 & 0.28 & 29 & 29 & 29 \\
\hline 405701 & -0.11 & -0.09 & 0.10 & 0.10 & 40 & 43 & 45 \\
\hline 412901 & 0.24 & 0.12 & 0.24 & 0.24 & 11 & 9 & 36 \\
\hline 413101 & 0.30 & 0.13 & 0.22 & 0.22 & 9 & 8 & 38 \\
\hline 413201 & -0.17 & -0.09 & 0.40 & 0.40 & 44 & 42 & 20 \\
\hline 420401 & 0.09 & 0.04 & 0.25 & 0.25 & 21 & 21 & 33 \\
\hline 423701 & -0.01 & -0.01 & 0.39 & 0.39 & 31 & 31 & 23 \\
\hline 424401 & -0.05 & -0.01 & 1.00 & 6.83 & 35 & 34 & 1 \\
\hline 480201 & 0.44 & 0.16 & 0.46 & 0.46 & 3 & 3 & 11 \\
\hline 512901 & 0.08 & 0.03 & 0.52 & 0.52 & 24 & 24 & 6 \\
\hline 52401 & 0.66 & 0.18 & 1.00 & 2.51 & 2 & 2 & 2 \\
\hline 538501 & -0.14 & -0.05 & 0.54 & 0.54 & 41 & 39 & 4 \\
\hline 545601 & -0.55 & -0.36 & 0.18 & 0.18 & 46 & 46 & 44 \\
\hline 753801 & 0.27 & 0.11 & 0.40 & 0.40 & 10 & 10 & 19 \\
\hline 763401 & 0.12 & 0.07 & 0.20 & 0.20 & 18 & 17 & 40 \\
\hline 768901 & -0.03 & -0.01 & 0.29 & 0.29 & 33 & 33 & 27 \\
\hline 78101 & 0.03 & 0.01 & 0.27 & 0.27 & 28 & 28 & 30 \\
\hline 804801 & 0.44 & 0.16 & 0.46 & 0.46 & 4 & 4 & 12 \\
\hline 81101 & 0.12 & 0.05 & 0.25 & 0.25 & 19 & 19 & 32 \\
\hline 81201 & 0.08 & 0.04 & 0.25 & 0.25 & 23 & 23 & 34 \\
\hline 816801 & 0.13 & 0.06 & 0.32 & 0.32 & 17 & 18 & 24 \\
\hline 81801 & 0.37 & 0.13 & 0.44 & 0.44 & 7 & 6 & 14 \\
\hline 866501 & 0.01 & 0.00 & 0.29 & 0.29 & 30 & 30 & 28 \\
\hline
\end{tabular}


Table 3: Market Neutral performance (5 years)

\begin{tabular}{|c|c|c|c|c|c|c|c|}
\hline Funds & Sharpe ratio & $\begin{array}{c}\text { Modified } \\
\text { Sharpe }\end{array}$ & DEA ratio & $\begin{array}{c}\text { DEA Super- } \\
\text { efficiency }\end{array}$ & $\begin{array}{c}\text { Sharpe } \\
\text { Ranking }\end{array}$ & $\begin{array}{c}\text { Modified } \\
\text { Sharpe Ranking }\end{array}$ & $\begin{array}{c}\text { super DEA } \\
\text { Ranking }\end{array}$ \\
\hline 144001 & -0.18 & -0.07 & 0.36 & 0.36 & 45 & 45 & 33 \\
\hline 144201 & -0.16 & -0.06 & 0.36 & 0.36 & 42 & 42 & 31 \\
\hline 146701 & 0.14 & 0.05 & 1.00 & 1.01 & 15 & 8 & 4 \\
\hline 146901 & 0.20 & 0.06 & 0.35 & 0.35 & 4 & 5 & 35 \\
\hline 166301 & -0.16 & -0.06 & 0.64 & 0.64 & 43 & 43 & 12 \\
\hline 169101 & 0.11 & 0.04 & 0.29 & 0.29 & 17 & 16 & 43 \\
\hline 189501 & 0.01 & 0.00 & 0.88 & 0.88 & 30 & 30 & 9 \\
\hline 20201 & 0.85 & 0.24 & 1.00 & 2.15 & 1 & 1 & 1 \\
\hline 204001 & 0.07 & 0.03 & 0.28 & 0.28 & 22 & 18 & 46 \\
\hline 219401 & -0.07 & -0.03 & 0.29 & 0.29 & 38 & 39 & 44 \\
\hline 25901 & 0.07 & 0.02 & 0.31 & 0.31 & 24 & 24 & 39 \\
\hline 26001 & -0.02 & -0.01 & 0.88 & 0.88 & 32 & 31 & 8 \\
\hline 271201 & -0.04 & -0.01 & 0.68 & 0.68 & 33 & 33 & 11 \\
\hline 274901 & 0.20 & 0.09 & 0.36 & 0.36 & 5 & 3 & 32 \\
\hline 300101 & 0.10 & 0.02 & 0.48 & 0.48 & 19 & 22 & 18 \\
\hline 334101 & 0.18 & 0.06 & 0.50 & 0.50 & 7 & 6 & 16 \\
\hline 346501 & 0.11 & 0.04 & 0.38 & 0.38 & 18 & 11 & 28 \\
\hline 350801 & 0.01 & 0.00 & 0.31 & 0.31 & 29 & 29 & 40 \\
\hline 370601 & -0.17 & -0.06 & 0.56 & 0.56 & 44 & 44 & 13 \\
\hline 382001 & 0.07 & 0.02 & 0.35 & 0.35 & 23 & 21 & 34 \\
\hline 382101 & 0.18 & 0.05 & 0.43 & 0.43 & 9 & 9 & 22 \\
\hline 382401 & 0.15 & 0.04 & 0.50 & 0.50 & 14 & 14 & 17 \\
\hline 390201 & 0.12 & 0.02 & 0.91 & 0.91 & 16 & 20 & 5 \\
\hline 398501 & 0.08 & 0.02 & 0.40 & 0.40 & 21 & 23 & 24 \\
\hline 405701 & 0.08 & 0.02 & 0.31 & 0.31 & 20 & 19 & 41 \\
\hline 412901 & 0.04 & 0.01 & 0.55 & 0.55 & 28 & 28 & 14 \\
\hline 413101 & -0.02 & -0.01 & 0.46 & 0.46 & 31 & 32 & 21 \\
\hline 413201 & -0.07 & -0.02 & 0.46 & 0.46 & 37 & 34 & 20 \\
\hline 420401 & -0.09 & -0.03 & 0.34 & 0.34 & 41 & 41 & 36 \\
\hline 423701 & 0.19 & 0.06 & 0.53 & 0.53 & 6 & 7 & 15 \\
\hline 424401 & 0.17 & 0.04 & 0.69 & 0.69 & 10 & 15 & 10 \\
\hline 480201 & 0.16 & 0.04 & 0.39 & 0.39 & 11 & 12 & 26 \\
\hline 512901 & 0.18 & 0.03 & 1.00 & 1.59 & 8 & 17 & 2 \\
\hline 52401 & 0.77 & 0.21 & 1.00 & 1.21 & 2 & 2 & 3 \\
\hline 538501 & 0.05 & 0.01 & 0.90 & 0.90 & 27 & 27 & 7 \\
\hline 545601 & -0.32 & -0.10 & 0.31 & 0.31 & 46 & 46 & 38 \\
\hline 753801 & 0.15 & 0.05 & 0.42 & 0.42 & 13 & 10 & 23 \\
\hline 763401 & -0.07 & -0.02 & 0.29 & 0.29 & 36 & 37 & 45 \\
\hline 768901 & -0.08 & -0.03 & 0.48 & 0.48 & 40 & 40 & 19 \\
\hline 78101 & -0.06 & -0.02 & 0.33 & 0.33 & 34 & 36 & 37 \\
\hline 804801 & 0.16 & 0.04 & 0.39 & 0.39 & 12 & 13 & 27 \\
\hline 81101 & -0.08 & -0.02 & 0.37 & 0.37 & 39 & 38 & 29 \\
\hline 81201 & -0.06 & -0.02 & 0.37 & 0.37 & 35 & 35 & 30 \\
\hline 816801 & 0.06 & 0.01 & 0.90 & 0.90 & 25 & 26 & 6 \\
\hline 81801 & 0.26 & 0.07 & 0.31 & 0.31 & 3 & 4 & 42 \\
\hline 866501 & 0.05 & 0.02 & 0.40 & 0.40 & 26 & 25 & 25 \\
\hline
\end{tabular}

Tables 4 and 5 present the correlation coefficients of the different performance measures for the 3 - and 5year periods, respectively. The results shown in these two tables confirm our earlier observations. The correlation coefficients for the Sharpe and Modified Sharpe ratios are very high for all HF classes except Short Selling, while the correlation between the Super-DEA score and the two Sharpe ratios is weak. For example, for the 3-year period, the correlation coefficient between the Sharpe and Modified Sharpe ratios is $0.92(t$-statistic $=10.58)$ while those between the Sharpe ratio and the Super-DEA score and between the Modified Sharpe and DEA score, are $0.58(t$ statistic $=3.07)$ and $0.37(t$-statistic $=1.74)$, respectively. 
Table 4: Correlation coefficient ( 3 years)

(Correlation coefficients are in bold and the t-statistics are in the parenthesis)

\begin{tabular}{lccc}
\hline & $\begin{array}{c}\text { Sharpe and Modified } \\
\text { Sharpe (t-stat) }\end{array}$ & $\begin{array}{c}\text { Sharpe and Super DEA } \\
\text { (t-stat) }\end{array}$ & $\begin{array}{c}\text { Modified Sharpe and Super DEA (t- } \\
\text { stat) }\end{array}$ \\
\hline Convertible Arbitrage & $\mathbf{0 . 9 2}(10.59)$ & $\mathbf{0 . 5 8}(3.07)$ & $\mathbf{0 . 3 7}(1.74)$ \\
Distressed Securities & $\mathbf{0 . 9 9}(30.10)$ & $\mathbf{0 . 7 0}(4.83)$ & $\mathbf{0 . 6 4}(4.03)$ \\
Equity Hedge & $\mathbf{0 . 9 9}(99.84)$ & $\mathbf{0 . 0 6}(0.78)$ & $\mathbf{0 . 0 6}(0.86)$ \\
Event Driven & $\mathbf{0 . 9 4}(19.39)$ & $\mathbf{0 . 2 5}(1.74)$ & $\mathbf{0 . 0 8}(0.58)$ \\
Fixed Income Arbitrage & $\mathbf{0 . 9 7}(26.92)$ & $\mathbf{0 . 4 2}(3.22)$ & $\mathbf{0 . 2 9}(2.09)$ \\
Funds of Funds & $\mathbf{0 . 9 8}(68.94)$ & $\mathbf{0 . 3 0}(4.15)$ & $\mathbf{0 . 2 2}(3.08)$ \\
Global Macro & $\mathbf{0 . 9 7}(24.18)$ & $\mathbf{0 . 4 5}(2.93)$ & $\mathbf{0 . 4 3}(2.77)$ \\
Market Neutral & $\mathbf{0 . 9 9}(61.34)$ & $\mathbf{0 . 3 5}(2.48)$ & $\mathbf{0 . 3 3}(2.33)$ \\
Short Selling & $\mathbf{0 . 6 1}(2.40)$ & $\mathbf{0 . 5 1}(1.88)$ & $\mathbf{- 0 . 0 3}(-0.09)$ \\
\hline
\end{tabular}

Table 5: Correlation coefficient (5 years)

(Correlation coefficients are in bold and the t-statistics are in the parenthesis)

\begin{tabular}{lccc}
\hline & $\begin{array}{c}\text { Sharpe } \\
\text { Hedge funds strategies }\end{array}$ & $\begin{array}{c}\text { Sharpe } \\
\text { and Modified Sharpe }\end{array}$ & $\begin{array}{c}\text { Modified Sharpe } \\
\text { and Super DEA }\end{array}$ \\
\hline Convertible Arbitrage & $\mathbf{0 . 9 9}(30.00)$ & $\mathbf{0 . 4 3}(2.08)$ & $\mathbf{0 . 4 1}(1.97)$ \\
Distressed Securities & $\mathbf{0 . 9 6}(17.70)$ & $\mathbf{0 . 5 3}(3.05)$ & $\mathbf{0 . 3 9}(2.09)$ \\
Equity Hedge & $\mathbf{0 . 9 7}(54.72)$ & $\mathbf{0 . 4 3}(7.24)$ & $\mathbf{0 . 4 0}(6.02)$ \\
Event Driven & $\mathbf{0 . 9 4}(18.54)$ & $\mathbf{0 . 1 4}(0.99)$ & $\mathbf{0 . 2 8}(1.98)$ \\
Fixed Income Arbitrage & $\mathbf{0 . 9 8}(35.56)$ & $\mathbf{0 . 2 8}(3.90)$ & $\mathbf{0 . 1 1}(0.76)$ \\
Funds of Funds & $\mathbf{0 . 9 9}(91.70)$ & $\mathbf{0 . 4 6}(2.96)$ & $\mathbf{0 . 2 2}(3.09)$ \\
Global Macro & $\mathbf{0 . 9 0}(12.08)$ & $\mathbf{0 . 2 3}(1.58)$ & $\mathbf{0 . 4 7}(3.02)$ \\
Market Neutral & $\mathbf{0 . 9 8}(34.36)$ & $\mathbf{- 0 . 0 8}(-0.24)$ & $\mathbf{0 . 1 9}(1.31)$ \\
Short Selling & $\mathbf{0 . 8 3}(4.64)$ & & $\mathbf{0 . 2 3}(0.74)$ \\
\hline
\end{tabular}

The correlation is much weaker between the DEA score and the two ratios. For the 3-year period, the correlation is however more higher for the Sharpe ratio and DEA score than for the Modified Sharpe ratio and the DEA score. Indeed, five out of nine categories exhibit a positive correlation between the Sharpe ratio and DEA score, while only three categories show a positive correlation between the Modified Sharpe ratio and the DEA score.

\subsection{Comparison of the different measures with stochastic dominance}

The results of the previous section do not allow us to confirm which of the measures-the Sharpe ratios or the DEA score_-produces the "right" ranking. In this section, we compare the results of the three methods studied in relation to the ranking obtained using the stochastic dominance method.

We have performed computation on four HF categories. Results presented in Table 6 are only for the Market Neutral category over a 3-year period. Results for the Event Driven, Global Macro, and Fixed Income Arbitrage categories are available from the author.

The five highest ranked funds for each of the measures studied are shown in bold type. In light of the ranking obtained using stochastic dominance, we conclude that the results produced using the Super-DEA method are not as good as those obtained with the Sharpe ratios. For example, the 382101 Fund is ranked first, seventh, fifth and fifteenth, using stochastic dominance (SD), the Sharpe Ratio (SR), Modified Sharpe (MSR) and the DEA score, respectively. Furthermore, the 424401 Fund is ranked first with the DEA method, while it is ranked respectively $39^{\text {th }}, 38^{\text {th, }}$ and $34^{\text {th }}$ with the SD, SR, and MSR methods. 
Table 6: Ranking comparison for market neutral strategy (3 years)

\begin{tabular}{|c|c|c|c|c|}
\hline Funds & Stochastic Dominance ranking & Sharpe ranking & Modified Sharpe ranking & Super-DEA ranking \\
\hline 144001 & 16 & 15 & 26 & 18 \\
\hline 144201 & 20 & 12 & 25 & 9 \\
\hline 146701 & 10 & 3 & 7 & 5 \\
\hline 146901 & 13 & 11 & 12 & 25 \\
\hline 166301 & 31 & 31 & 35 & 22 \\
\hline 169101 & 14 & 16 & 14 & 41 \\
\hline 189501 & 17 & 26 & 15 & 10 \\
\hline 20201 & 3 & 1 & 1 & 3 \\
\hline 204001 & 14 & 17 & 13 & 43 \\
\hline 219401 & 24 & 20 & 22 & 42 \\
\hline 25901 & 30 & 36 & 40 & 39 \\
\hline 26001 & 46 & 45 & 45 & 16 \\
\hline 271201 & 40 & 42 & 41 & 31 \\
\hline 274901 & 19 & 22 & 20 & 26 \\
\hline 300101 & 41 & 40 & 38 & 35 \\
\hline 334101 & 23 & 19 & 27 & 8 \\
\hline 346501 & 28 & 27 & 36 & 21 \\
\hline 350801 & 37 & 37 & 37 & 37 \\
\hline 370601 & 31 & 29 & 32 & 17 \\
\hline 382001 & 35 & 41 & 44 & 46 \\
\hline 382101 & 1 & 7 & 5 & 15 \\
\hline 382401 & 12 & 13 & 16 & 7 \\
\hline 390201 & 4 & 10 & 11 & 13 \\
\hline 398501 & 29 & 32 & 29 & 29 \\
\hline 405701 & 35 & 39 & 43 & 45 \\
\hline 412901 & 7 & 14 & 9 & 36 \\
\hline 413101 & 8 & 8 & 8 & 38 \\
\hline 413201 & 44 & 44 & 42 & 20 \\
\hline 420401 & 22 & 24 & 21 & 33 \\
\hline 423701 & 38 & 34 & 31 & 23 \\
\hline 424401 & 39 & 38 & 34 & 1 \\
\hline 480201 & 5 & 4 & 3 & 11 \\
\hline 512901 & 42 & 35 & 24 & 6 \\
\hline 52401 & 2 & 2 & 2 & 2 \\
\hline 538501 & 43 & 43 & 39 & 4 \\
\hline 545601 & 45 & 46 & 46 & 44 \\
\hline 753801 & 11 & 9 & 10 & 19 \\
\hline 763401 & 18 & 18 & 17 & 40 \\
\hline 768901 & 33 & 30 & 33 & 27 \\
\hline 78101 & 21 & 23 & 28 & 30 \\
\hline 804801 & 5 & 5 & 4 & 12 \\
\hline 81101 & 25 & 21 & 19 & 32 \\
\hline 81201 & 25 & 25 & 23 & 34 \\
\hline 816801 & 27 & 28 & 18 & 24 \\
\hline 81801 & 9 & 6 & 6 & 14 \\
\hline 866501 & 34 & 33 & 30 & 28 \\
\hline
\end{tabular}

Table 7 presents the correlation coefficients of the three performance ranks with ranks obtained by stochastic dominance method for the 3-year period. The results shown in this table confirm our earlier observations. The correlation coefficients for the Sharpe and Modified Sharpe ratios are higher for the four HF categories, while the correlation between the SD and Super-DEA rankings is the weakest. These observations reinforce the use of the Sharpe ratio or the Modified Sharpe ratio as a measure of hedge funds performance, even if the returns of this asset class do not follow a normal distribution of probability. 
Table 7: Correlation Coefficient ( 3 years)

(Correlation coefficients are in bold and the t-statistics are in the parenthesis)

\begin{tabular}{lccc}
\hline Hedge funds strategy & $\begin{array}{c}\text { Sharpe } \text { and stochastic } \\
\text { dominance }\end{array}$ & $\begin{array}{c}\text { Modified Sharpe } \text { and } \\
\text { stochastic dominance }\end{array}$ & $\begin{array}{c}\text { DEA and stochastic } \\
\text { dominance }\end{array}$ \\
\hline Event Driven & $\mathbf{0 . 8 1}(9.04)$ & $\mathbf{0 . 8 8}(12.13)$ & $\mathbf{0 . 1 5}(0.97)$ \\
Fixed Income Arbitrage & $\mathbf{0 . 7 6}(7.72)$ & $\mathbf{0 . 8 2}(9.46)$ & $\mathbf{0 . 2 6}(1.78)$ \\
Global Macro & $\mathbf{0 . 7 5}(6.56)$ & $\mathbf{0 . 8 3}(8.71)$ & $\mathbf{0 . 2 8}(1.67)$ \\
Market Neutral & $\mathbf{0 . 9 6}(23.66)$ & $\mathbf{0 . 9 3}(16.21)$ & $\mathbf{0 . 2 4}(1.64)$ \\
\hline
\end{tabular}

\section{CONCLUSION}

The objective of this study was to review performance measurement methods and compare them with rankings obtained using the stochastic dominance method. Tests were conducted on four hedge fund categories: Market Neutral, Global Macro, Fixed Income Arbitrage, and Event Driven. We find that DEA and stochastic dominance results are weakly correlated, while the results of the two other more traditional measures (Sharpe and Modified Sharpe ratios) are strongly correlated with those of stochastic dominance.

These findings show that, despite its relative simplicity, the Sharpe ratio is still an effective measure for evaluating HF performance, even when their returns do not follow normal distribution. For further research, it would be worth exploring the reliability of the Sharpe and Modified Sharpe ratios based on a simulation of extreme return distribution.

\section{AUTHOR INFORMATION}

Dr. Komlan Sedzro is full professor of finance and a former Director, M.Sc. Program in Finance, University of Quebec at Montreal. He obtained his Ph.D. in 1992 from Laval University, and since then has published many peerreviewed articles on corporate finance, banking, mutual and hedge funds.

\section{REFERENCES}

1. Ackermann, C., R. Mcnally, and D. Ravenscraft, 1999. The Performance of Hedge Funds: Risks, Return and Incentives, Journal of Finance 54, 833-874.

2. Agarwal, V., and N. Naik, 2000a, On Taking the Alternative Route: Risks, Rewards, and Performance Persistence of Hedge Funds, Journal of Alternative Investments 2, 6-23.

3. Agarwal, V., and N. Naik, 2000b. Multi-Period Performance Persistence of Hedge Funds, Journal of Financial and Quantitative Analysis 35, 327-342.

4. Anderson, P., and N. C. Petersen, 1993. A Procedure for Ranking Efficient Units in Data Envelopment Analysis, Management Science 39, 1261-1264.

5. Banker, R. D., R. J. Kauffman, and R. C. Morey, 1986. Measuring Gains in Operational Efficiency from Information Technology: A Study from Positrian Deployment at Harvee's inc, Journal of Management Information Systems 32, 29-54.

6. Banker, R. D., R. J. Kauffman, and R. Strauss, 1988. A Comparative Application of Data Envelopment Analysis and Translog Methods: An Illustrative Study of Hospital Production, Management Science 13, 4552.

7. Bessent, A., and W. Bessent, 1980. Determining the Comparative Efficiency of Schools through Data Envelopment Analysis, Education Administration 16, 57-75.

8. Brown, S. J., W. Goetzmann, and R. Ibbotson, 1999. Offshore Hedge Funds: Survival and Performance, 1989-95, Journal of Business 72, 91-117.

9. Caglayan, M. O., and F. R. Edwards, 2001. Hedge Funds Performance and Manager Skill, Journal of Futures Markets 21, 1003-1028.

10. Charnes, A., W. Cooper, and E. Rhodes, 1978. Measuring the Efficiency of Decision Making Units, European Journal Operational Research 2, 429-444.

11. Charnes, A., W. Cooper., and L. Seiford, 1995. Data Envelopment Analysis: Theory, Methodology and Applications, Kluwer Academic Publishers, Boston, USA. 
12. Cottier, P., 2000. Hedge Funds and Managed Futures, $3^{\text {rd }}$ edition, Verlag Paul Haupt Bern.

13. Crockett, A., 2007. Evolution et Régulation des Hedge funds, Banque de France, Revue de la Stabilité financière 10, 19-29.

14. Davidson, R., J. Y. Duclos, 2000. Statistical Inference for Stochastic Dominance and for the Measurement of Poverty and Inequality, Econometrica 68, 1435-1464.

15. Elton, E. J., and M. J. Gruber, 1995. Modern Portfolio Theory and Investment Analysis, $5^{\text {th }}$ edition. NewYork: John Wiley \& Sons.

16. Favre, L., and J-A Galeano, 2002. Mean-Modified Value-at-Risk Optimization with Hedge Funds, Journal of Alternative Investment 5, 2002, 21-25

17. Gregoriou, G., K. Sedzro, and J. Zhu, 2005. Hedge Fund Performance Appraisal Using Data Envelopment Analysis, European Journal of Operational Research 164, 2005, 555-571.

18. Liang, B., 1999. On the Performance of Hedge Funds, Financial Analyst Journal 55, 72-85.

19. Meyer, T. O., X. M. Li, and L. C. Rose, 2005. Comparing Mean Variance Tests with Stochastic Dominance Tests when Assessing International Portfolio Diversification Benefits, Financial Services Review 14, pp. 149-169.

20. Murthi, B. P. S, K. Y. Choi, and P. Desai, 1997. Efficiency of Mutual Funds and Portfolio Performance Measurement: A Non-Parametric Approach, European Journal of Operational Research, 98, 408-418.

21. Post, T, 2003. Empirical Tests for Stochastic Dominance Efficiency, Journal of Finance 58, 1905-1931.

22. Sharpe, W., 1966. Mutual funds Performance, Journal of Business 39, 119-138.

23. Sherman, H., and F. Gold, 1985. Bank Branch Operating Efficiency: Evaluation with Data Envelopment Analysis, Journal of Banking and Finance 9, 297-315.

24. Taylor, W., and J. Yoder, 1999. Load and No-Load Mutual Fund Dynamics during the 1987 market Crash, Journal of Economics and Finance 23, pp. 155-165.

25. Wong Wing-Keung, Kok Fai Phoon, and Hooi Hooi Lean, 2008. Stochastic dominance Analysis of Asian Hedge Funds, Pacific-Basin Finance Journal 16, 204-223. 


\section{NOTES}

